\title{
ENTERPRENEURAL ENVIRONMENT \& CROSS-CULTURIAL MANAGEMENT: A ROAD MAP FOR SUSTAINING AFRICAN DEVELOPMENT
}

\author{
Ellis I. Idemobi
}

Chukwuemeka Odumegwu Ojukwu University, Igbariam Campus

\author{
\&
}

\author{
Gabriel A. Onukwuli
}

Federal College of Education (Technical), Umunze

\begin{abstract}
For African operations to succeed in Western countries, African entrepreneurs must embrace entrepreneurs' environmental management competencies as part of a strategic focus for crosscultural management. This article examines entrepreneurial environment and cross-cultural management as a road map of sustaining African development. The specific objectives are to explore the relationship between entrepreneurial environment and cross-cultural management; to examine why cross-cultural orientation is important in African entrepreneurs; and to determine the effect of globalization on entrepreneurial environment and cross-cultural management. This paper argued that entrepreneurial culture, environmental turbulence and global network competencies improve the relationship between entrepreneurial environment and cross-cultural management. Therefore, by drawing insights from the existing review of the literature, our purpose is to improve understanding of the relationship between entrepreneurial environment and cross-cultural management under the moderating effects of entrepreneurial culture, macro environment and global network competence. A model of entrepreneurial environment and cross-cultural management is also suggested to provide useful insights in the context of African entrepreneurs.
\end{abstract}

Keywords: Entrepreneurial Culture, Environmental Turbulence, Network Competence, Entrepreneurial Environment, Cross-Cultural Management.

\section{Introduction}

A road map of escaping the present economic recession and sustaining development is the study of entrepreneurial environment and cross-cultural management. Entrepreneurial Environmental Competencies are essential to the success of cross-cultural management for sustainable development in the competitive and rapidly changing business environment (Sajilan \& Telisean, 2015). Entrepreneurial competencies alone do not lead to the success of African entrepreneurs, because many external factors such as environment play a vital role in the entrepreneurial business as well (Dess \& Beard; Sajilan \& Telisean, 2015). Thus, the success of entrepreneurial business is contingent upon the environmental turbulence as well. For instance, in the context of African society, the external environment is highly turbulent. Environmental turbulence indicates an inability to predict rapid change in economic conditions.

The quality of life brings into focus the concept of environment (Egunjobi, 1993). Therefore, development activities to meet human needs must proceed within acceptable environment limits as way by which the objective of sustainable development can be achieved. The existing research have revealed the important of entrepreneurial environmental and general consensus among scholars that culture orientations play a vital role in development of cross-cultural entrepreneurship management (Ahmed, 2007; Amoako-Agyei, 2009). Gutterman (2017) 
indicated that sustainable African entrepreneurship is heavily dependent on comparatives management studies, which include research activities undertaken to identify and explain similarities and differences among business strategies, management styles, systems and social behaviours in different work content (geographic areas, cultures or industries).

Amoako-Agyie (2009) asserts that for African entrepreneurs to succeed in Western culture, African executives must embrace cross-cultural management skills as part of a broad strategic focus. Therefore, for African entrepreneurs to globalize successfully into marketplace, the effective cross-cultural entrepreneur must have an indebt understanding of Western cultural values system. For example, what may be acceptable in Nigeria may be offensive in America. Many of the ends or objectives may be the same, but way of communication and business styles are likely differing. Ascertaining the differences will come easily to African entrepreneur who is well accustomed in the complexities of core American cultural values and social norms in commercial environment.

Linton (2014) opined that proper alignment among external and internal entrepreneurial organizational factors will positively impact on organizational performance and its success. Many management scholars perceive culture as a negative factor that needs to be controlled and contained in its impact, as it renders the application of best management practice difficult (Pudelko, Carr and Henley, 2014). Studies have shown that globalization has however, forced the globe to confront behavioural differences across countries and thus place greater emphasis on culture as an important source of competitive advantage, particularly when the differences are managed thoughtfully (Ahmad, 2007; Amoako-Agyyei, 2009; Sajilan and Tehsean, 2015; and Gutterman, 2017). The problem of this study is on how entrepreneurial environmental and cross-cultural management should be addressed so as to achieve sustainable development in Africa. The objectives of this study are three-fold: (i) To explore the relationship between entrepreneurial environment and cross-cultural management; (ii) To examine why crosscultural orientations is important to African entrepreneurs; and (iii) To determine the effect of globalization on entrepreneurial environment and cross-cultural management.

Overall, the study seeks a better understanding of entrepreneurial environment and crosscultural management for African sustainable development; to add to the literature on crosscultural management by considering African entrepreneurial environment as a subject matter and by extension, the result should allow more insights into the action of ethnic entrepreneurs and assist human resource management practitioners in assessing case of policy failure as well as management diversity initiatives.

\section{Literature Review \\ Conceptual Framework}

Sada in Egunjobi (1993) defines environment as a system within which living organism interact with the physical elements; while entrepreneurial environment is the system within which entrepreneurial business interact for survival. Entrepreneurial environment requires entrepreneurial competence as indicated by Ahmad (2007) study on cross-cultural competence and entrepreneurial success in SMEs in Australia and Malaysia. He defines entrepreneurial competence as underlying characteristics such as generic and specific knowledge, motives, traits, self-image, social roles and skills which result in venture birth, survival, and/or growth in improving a firm performance. Brophy and Kiely in Ahmad (2007) assert that competencies of key players in organization offer the reason why some entrepreneurs fail and others succeed in similar situations. 
Along with the advantages of operating internationally comes cross-cultural organizational complexity. Culture forms a basis and outcome of independent transaction in business, be it national or international. Hofstede in Wilson (2012) defined culture as a collective programming of mind which distinguishes the member of one human group from another. It includes values, ideas and norms that are shared among a group of people and which when taken together constitute a design for living. Harris and Robert in Pudleko, Carr and Henley (2014) defined cross-cultural management as those procedures and policies that moderate impact of cultural differences on execution of management tasks and promote cross-cultural sensitivity.

\section{Theoretical Exposition}

This study anchors on the strategic contingency theory. The strategic contingency theory is based on the assumption that the organizational resources must match or fit with external environment context. It is also believed that no such universal strategies exist that are optional for all business, regardless of position of their sources with the environmental context (Ginsberg and Venkatrman in Sajilan and Tehseen, 2015). The proper fitness in the contingency theory adduces that proper alignment among external and internal organizational factors will positively impact on organizational performance and its success (Linton, 2014). He added that "contingency fit" represents matching, aligning or consistency of the organizational components with its context that leads to organizational performance. Therefore, there is no single way to organize and no single way of organizing is effective under all situations. The importance of this theory to the study, is that entrepreneurial competencies should match with the entrepreneurs environment and cross-cultural management of businesses so as to face the threats and to avail possible opportunities. In other words, African entrepreneurs should be competent enough to face cross-cultural and rapid changing business environments to maintain business success and stability in highly turbulent environment.

\section{Entrepreneurial Environment and Cross-Cultural Management}

Entrepreneurial competences alone do not lead to success entrepreneurs businesses in Africa, many external factors such as environment plays a vital role in the success of entrepreneurs business as well (Sajilan and Tehseen, 2015). One of the basic premises for sustainable development is recognition that environment and development are not exclusive of one another but complementary and independent and in long run mutually reinforcing (Ahmad and Sammy in Egunjobi, 1993). The issue of the quality of life brings into focus the concept of environment. Wilson, (2012) assert that development activities to meet human needs must proceed within acceptable environmental limits. He concluded that in context of Nigeria and most African countries, the external environment is highly turbulence. Thus, the success of entrepreneurship business is contingent upon the environmental turbulence as well. Such turbulence environment include deforestation, deterioration of urban physical quality, land degradation, soil erosion and flooding, inability to predict changes in economic activities, technology, competitors action and customers preference (Sajilan and Tehseen, 2015).

Entrepreneurial culture is contributing factor and an outcome of the business macro environment comprised of religious effects, political forces, legal system, economic conditions, socio-demographic structure, and technological environment (Wilson, 2012). Under entrepreneurial culture, the individual's cultural profile and behaviour are shared by family educational systems and institutions (Schools and Universities), personal network and other conditions (Wilson, 2012). 
As entrepreneurial venture grows, expands globally and mature, sound management as opposed to purely entrepreneurial drive becomes increasingly importance (Ahmad, 2007). Initiation of international business venture requires complex research of products, markets, technologies, financing, cost analysis, legal issues, global positioning, entry strategy and other issues. These activities involve reading, listening, negotiating international with others (Wilson, 2012). Furthermore, international marketing includes collection of information network, where personal connections and other informal aspects are paramount. Sajilan and Tehseen (2015) explored the relationship between entrepreneurs and business success and also highlight the impact of cultural orientations on the development of competencies of ethnic entrepreneurs in the context of Malaysian SMEs. The article revealed the important contribution of the business environment as a moderator to improve the relationship between entrepreneurial competencies and SMEs business success in different context. Also, high environmental turbulence is assumed around Malaysian SMEs. Therefore, it is expected that level of SMEs' network competence will contribute more towards the business success in the context of Malaysian SMEs.

Egunjobi (1993) examines issues in environmental management for sustainable development in Nigeria using ardent literature on the subject matter. The study concluded that Nigeria needs the necessary technical, administrative and legislature back-up for more effective integration of environmental concern with national and local development policies. Furthermore, the recognition of environmental impact assessment as a vital management tool to achieve development supported with adequate facilities. The moderating role of dynamic environment in relation to other organization variables and firm performance is well documented in literature. For instance, Ahamd (2007) used perceived environment as a moderator between entrepreneurial competencies and business success; Egunjobi (1993) studied issues in environmental management for sustainable development. Likewise, the environmental turbulence is widely used as exogenous variable with its moderating effect (Chin and Sun in Moore, 2014; Zhang and Duan in Sajilan and Tehseen, 2015).

\section{Why Cross-Cultural Orientation is Important to African Entrepreneurs}

The process and outcome of entrepreneurship are affected by many conditions with culture playing a crucial but often invisible, "Soft" role compared to "hard" variables - Finance, strategy or law (Wilson, 2012). He added that among numerous practical cultural applications in global entrepreneurs key areas are international marketing, international negotiation and international management. Culture creates values which are most critical elements that link all aspects of behavior and impact on corporate strategy and organizational structure (Sajilan and Tehseen, 2015). Culture plays an important role in cross-cultural management orientations and cross-cultural research have uncovered evidence regarding cultural differences that can be used in a number of ways by global managers. It is at critical importance to note that there is no "one" African culture or society. Amoako-Agyei (2009) noted with instance, that Africa is vast, comprising 54 independent nations, about 900 million people and 3000 ethnic groups speaking or more than 1000 indigenous languages - in addition to the six European languages (English, French, Portuguese, German, Spanish and Italian) carried over from prior colonization.

Hofstede in Pudelico, Carr and Henley (2014) indicated that the business of international business is culture and that globalization has, however, forced us to confront behavioural differences across countries and thus to place greater emphasis on culture as an important variable. Gutterman (2017) outlined the reasons why cross-cultural orientation is important in Africa and the globe in general, they include (i) Knowledge regarding culture and what are 
considered to be effective, legitimate leadership, management styles and behaviours can be used in operating and managing foreign subsidiaries and in designing orientation and training programs for employees of global organizations; (ii) Information from cross-cultural research can be used in training organizational leaders to ensure that they understand and execute behaviours that are culturally appropriate and which are perceived as being positive and effective by their followers; (iii) A related issue is making sure that the management strategies and procedures used by organization leaders take into account cultural differences; (iv) Cultural orientation is also essential when negotiating and managing cross-border business relationship with partners from different societal cultures; (v) Finally societal cultures are key and inescapable part of external environment for all organizations and thus, this must be considered when designing and executing organizational strategies.

Amoako-Agyei (2009) study on culture as a crucial dimension to forging strong social, economic and diplomatic ties between Africa and Western World, the article clarifies the key roles that African culture plays in management methods, organizational behavior and business practices in Sub-Saharan region. The study concluded that for Western companies to succeed and lessen the likelihood of failure in Africa business environment, Western companies must embrace cross-cultural management skills as an integral part of a board strategic focus. Moore, (2014) takes an ethnographic study of the recruitment of women at Angola-German Automobile factory between 2003 and 2006 as a basis to explore the impact of the concepts of native categories on diversity management and cross-cultural management. Ethnographic research method was employed involving observation interviews and archival research. The finding suggest that native categories provide one reason why diversity management initiatives can fail to transfer, or why the introduction of, for instance affirmative action schemes may produce little practical result bar. The implication of this result involved in cross-cultural management activities particularly regarding diversity, need to be aware of the existence of nature categories, recontexualisation and potential impact on cross-cultural management and the implementation of diversity management policies.

Garcia-Cabrera \& Garcia-Soto (2008) researched on cultural differences and entrepreneurial behaviour: an intra country cross-cultural analysis in Cape Verde. The specific objectives are to examine the cultural values associated in literature with venture creation generalizable cultural contexts and to determine their intra-cultural differences in a country generating in entrepreneur behaviour of its population. Survey design method was employed with a sample of 488 individuals, obtained in the Republic of Cape Verde and analysed in six territories within the country. The result of the study confirms the existence of cultural differences in individualism between regions of the Republic of Cape Verde, as well as their capacity to explain entrepreneurial behavior in these regions.

Therefore, in a global worldwide continent of diversity, for African entrepreneurs to globalize into Western marketplace, African leaders must understand what is culturally expected of them for effective cross-cultural manager, this include developing an in-depth understanding of African and Western cultural values and its direct impact on business practices and organizational behavior (Amoako-Agyei, 2009).

\section{Effect of Globalization on Cross-Cultural Management}

In its broadcast sense Symonides in Ngige (2013) is of the view that globalization is generated by growing economic, cultural and political cooperation and links, as well as the needs to respond together to global problems which can be solved only on a planetary scale. The purpose 
of this paper subscribes to the viewpoint of cultural globalization. Globalization in this sense, conjures a borderless world with greater cultural integration that enhances the living standard of the people across the globe.

Hofstede in Wilson (2012) define culture as a collective programming of the mind which distinguishes the member of one human group from another. He further indicated that culture, a basis and outcome of interdependent transaction in business takes place on international, national, sub-national, regional, industry and corporate level. Harris and Moran in Puldelko, Carr and Henley (2014) concluded that essence of cross-cultural management is on those procedures and policies that moderate the impact of cultural differences on the execution of management task and promote cross-cultural sensitivity. For instance, a participant in a business transaction may be representing a certain nation, but his/her individual cultural profile based on this person's religious affliction, ethnic behavior norms, position in the national social satisfaction and other cultural traits.

Wilson (2012) indicated that one of the major cross-cultural differences in international entrepreneurship depends on the balance between content and context in communication between individuals affiliated with different national cultures. Hofstede cross-cultural study in Wilson (2012) surveyed 116,000 respondents from over seventy different countries around the World working in IBM's local subsidiaries in fifty countries and three regions from 1967-1973. The study reduced the World's vast cultural variety to six universal dimensions allowing for international comparison in managerial patterns as power distance, individualism, masculinity, uncertainty avoidance, long term orientation and indulgence.

As an entrepreneurial venture grows, expands globally and matures, sound management as opposed to purely entrepreneurial drive become increasingly important. Pudelico, Carr \& Henley (2014) examine globalization and its effect on international strategy and cross-cultural management using ardent literature. The study concluded that a new framework to overcome cross-cultural management as convergence versus divergence controversy. Personality traits, and cultural standards on behaviour and performance need to be taken into consideration by managers in order to increase intercultural performance. Furthermore, global managers must focus attention on vendor-customer relationships as strategies that leads to a better performance. Finally, in outsourcing at information technology (IT) and IT-enabled service, policy makers must go beyond more obvious cost issues to wider strategic consideration that are now coming into play.

\section{Proposed Theoretical Framework}

In the proposed theoretical framework, the entrepreneurial environment is treated as independent variables and cross-cultural management is the dependent variable, the framework takes into account the moderating role of entrepreneur organizational culture (routine behavior, dominant value, pattern in organization politic and corporate size). This is because research suggested that entrepreneurs/organizational culture form a basic outcome of independent transaction in business, be it national or international (Wilson 2012). The moderating impact of micro environmental turbulence is also considered in this framework, because many researchers such as (Sajilan \& Tehseen, 2015; Wilson, 2012) argued that the entrepreneurs perceptions and ways to deal with macro environment (religion political forces, legal system, economic condition, social-demographic structure and technological environment) impact cross-cultural management. Furthermore, this study also argues that keeping abreast with globalization through network competence will influence the success of cross-cultural 
management and will improve the relationship between the independent and the dependent variables in the framework of this study.

Consistent with the arguments of Sajilan \& Tehseen (2015) the present study will examine the entrepreneurial environment and cross-cultural management for sustainable African development. The organizational culture and macro environmental turbulence variables will be tested for its direct links to entrepreneurial cross-cultural management. The proposed framework is depicted in Figure 1.

\section{Figure 1: Proposed Entrepreneurial Environment/Cross-Cultural Management Framework}

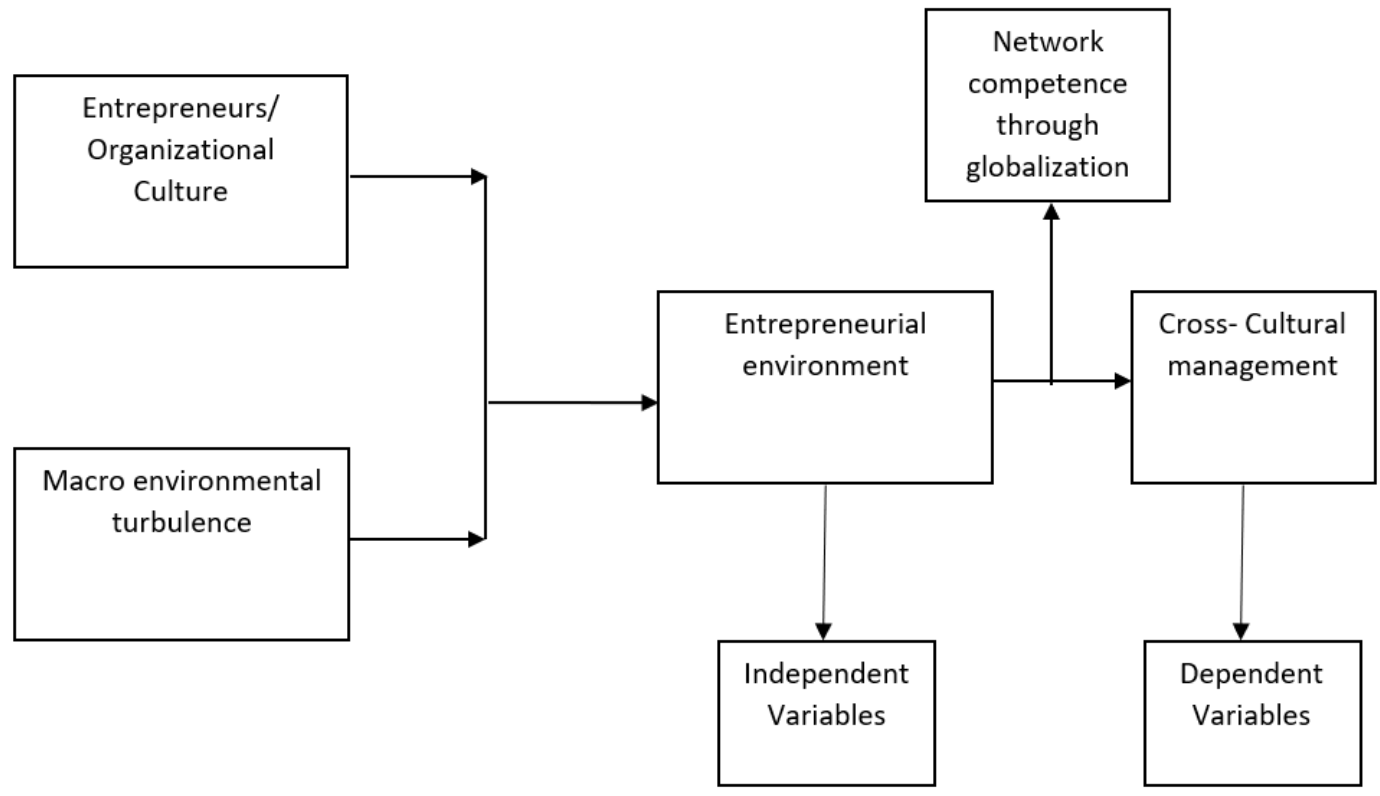

\section{Discussion and Conclusions}

Validating the entrepreneurial environment and cross-cultural management as a roadmap for African sustainable development has been addressed in the paper. A proposed validated model specifically in the context of African entrepreneurs will provide understanding regarding the importance of entrepreneurs' environment on the cross-cultural management. The study has revealed that entrepreneurs/organizational culture (routine behavior, dominant value, patterns in organizational politics and cooperate size); macro environment turbulence (religious effect, political forces, legal system, economic condition, socio-demographic structure and technological environment) and network of globalization are facets of entrepreneurial environment that impacts on cross-cultural management.

A single issue of journal cannot of course address all the issues outlined above; we have selected recent and tropical contributions that provide insight across the range of validating our study. The issue begins with a paper by Pudelico, Carr and Henley (2014) examines globalization and its effect on international strategy and cross-cultural management using ardent literature. The study concluded that personality traits, cultural standards, behaviour vendor-customer relationships, are strategies that lead to a better performance. 
Sajilan \& Tehseen (2015) explored the impact of cultural orientations on the development of competencies of ethnic entrepreneurs in the context of Malaysian SMEs. The article revealed the important contribution of the business environment, environmental turbulence and network competence as a moderator to improve the relationship between entrepreneurial competencies and SMEs business success in different context. In another development, Amoako-Agyei (2009) study on culture as a crucial dimension to forging strong social, economic and diplomatic ties between Africa and Western World, the study concluded that for western companies to succeed and lessen the likelihood of failure in Africa business environment, Western companies must embrace cross-cultural management skills as an integral part of a board strategic focus.

Garcia-Cabrera and Garcia-Soto (2008) researched on cultural differences and entrepreneurial behaviour: an intra country cross-cultural analysis in Cape Verde. The result of the study confirms the existence of cultural differences in individualism between regions of the Republic of Cape Verde, as well as their capacity to explain entrepreneurial behavior in these regions. In conclusion many researchers have perceive culture as a negative factor that needs to be controlled and contained in its impact, since it renders the application of best management practices difficult (Pudelko, Carr and Henley (2015). Others interpret culture as a source of competitive advantage. This study is of the opinion that entrepreneurs should build on cultural difference, no matter how they perceive culture; its effect needs to be managed.

\section{References}

Ahmad, N.H. (2007). Cross-cultural study of entrepreneurial competencies and entrepreneurial success in SMEs in Australia and Malaysia. A Thesis Submitted in the Fulfillment of Requirements for the Degree of Doctor of Philosophy, University of Adelaide, Australia.

Amoako-Agyei, E. (2009). Cross-cultural management and organizational behavior in Africa. Thunderbird International Business Review, 51(4): 330-339

Garcia-Cabrera, A.M. \& Garcia-Soto, M.G. (2008). Cultural differences and entrepreneurial behaviour: an intra-country cross-cultural analysis in Cape Verde. Entrepreneurship and Regional Development, 20(5) 451-483

Egunjobi, L. (1993). Issues in environmental management for sustainable development in Nigeria. The Environmentalist, 13(1): 33-40

Gutterman, A. (2017). Why cross-cultural studies is important for entrepreneurs. Retrieved from https:/www.linkedin.com on 25/4/2017

Linton, G. (2014). "Contingency Theory in Entrepreneurship research". Orebro University School Business.

Moor, F. (2015). An unsuitable job for a woman: a native category approach to gender, delivery and cross-cultural management. The International Journal of Human Resource Management, 26(2), 216-230.

Pudelko, M. Carr, C. \& Henley, J. (2014). Globalization and its effect on international strategy and cross-cultural management. International Studies of Management and Organization, 36(4), 3-8.

Sajila, S. \& Tehseen, S. (2015). Cultural orientation, entrepreneurial competencies and SMEs business success: the contingent roles of environmental turbulence and network competence. Society of Interdisciplinary Business Research, Retrieved from www. Sibresearch.org on 18/4/2017.

Wilson, J.M. (2012). Culture, communication and entrepreneurship. Retrieved from www. umacslowell.com on 25/4/2017. 